\title{
Advances in the Diagnosis and Treatment of Acute Pulmonary Embolism
}

\author{
Victor F. Tapson
}

Address: Division of Pulmonary and Critical Care Director, Center for Pulmonary Vascular Disease, Duke University Medical Center, Durham, NC 27710, USA

Email: tapso001@mc.duke.edu

Fl000 Medicine Reports 2012, 4:9 (doi:10.34I0/M4-9)

This is an open-access article distributed under the terms of the Creative Commons Attribution-Non Commercial License (http://creativecommons.org/licenses/by-nc/3.0/legalcode), which permits unrestricted use, distribution, and reproduction in any medium, provided the original work is properly cited. You may not use this work for commercial purposes.

The electronic version of this article is the complete one and can be found at: http://fl $000 . c o m / r e p o r t s / m / 4 / 9$

\begin{abstract}
Over the past two decades, considerable progress in technology and clinical research methods have led to advances in the diagnosis, treatment and prevention of acute venous thromboembolism. Despite this, however, the diagnosis is still often missed and preventive methods are often ignored. Published guidelines are useful, but are limited by the existing evidence base so that controversies remain with regard to topics such as duration of anticoagulation, indications for placement and removal of inferior vena caval filters, and when and how to administer thrombolytic therapy. The morbidity and mortality of this disease remain high, particularly when undiagnosed. While preventive approaches remain crucial, the focus of this review is on the diagnostic and therapeutic approach to acute venous thromboembolism, with an emphasis on acute pulmonary embolism.
\end{abstract}

\section{Introduction}

Venous thromboembolism includes the spectrum of deep venous thrombosis and pulmonary embolism. Acute pulmonary embolism is a worldwide problem responsible for 100,000 to 300,000 deaths per year in the United States alone [1-3], and it is commonly not diagnosed or even suspected until after the patient dies $[4,5]$. There should be a strong clinical suspicion of pulmonary embolism in settings with compatible symptoms (such as dyspnea and chest pain), particularly when risk factors are present. Unfortunately, in patients who die of acute pulmonary embolism, the clinical presentation is often atypical, making the diagnosis more challenging [5]. Therapy should be initiated and diagnostic testing undertaken when the disease is suspected $[1,6]$. This review will focus on the diagnostic and therapeutic approach to acute pulmonary embolism.

\section{Pathophysiology of acute pulmonary embolism}

The vast majority (95\%) of acute pulmonary embolism cases originate from thrombi in the leg or pelvic veins, although emboli may arise from other sources such as the axillary subclavian system or the renal veins [6]. Death from acute pulmonary embolism is caused by right ventricular failure. When thrombosis propagates from the calf veins to the larger more proximal veins, or originates more proximally, the likelihood of embolization, as well as the impact on the lungs, increases. As the embolic burden increases, right ventricular afterload increases and there is right ventricular dilation and hypokinesis associated with the increased pulmonary vascular resistance. When the clot burden reaches a critical threshold, the right ventricle is unable to generate enough force to achieve an adequate cardiac output and fails, resulting in hypotension and cardiac arrest. A crucial issue in acute pulmonary embolism is how to risk-stratify patients; i.e. how we translate the status of the patient, and particularly the right ventricle, into meaningful treatment decisions.

\section{Risk factors and diagnostic approach}

Idiopathic venous thromboembolism occurs, but most patients have one or more underlying risk factors arising from Virchow's triad of stasis, venous injury, or 
hypercoagulability (thrombophilia), (Table 1) [6,7]. When suspected, patients should undergo diagnostic testing and if there is a high clinical suspicion and low perceived risk of bleeding, therapy should be initiated during the diagnostic evaluation $[1,6,8]$. The spectrum of pulmonary embolism presentations ranges from asymptomatic/minimal symptoms to massive emboli causing sudden death or progressing rapidly to death from rightheart failure.

Dyspnea and chest pain are the most common symptoms of acute pulmonary embolism; these and other symptoms and signs are nonspecific (Table 2). While pulmonary embolism commonly presents with symptoms of sudden onset, as many as $25 \%$ of patients with proven acute pulmonary embolism relate their onset of their symptoms at more than two weeks prior to the time of diagnosis [9]. Contrary to popular teaching, chest wall tenderness can occur in acute pulmonary embolism because of pulmonary infarction [10]. Patients with acute pulmonary embolism may have no symptoms from the emboli; incidental pulmonary embolism is sometimes documented by computed tomographic angiography (CTA) [6]. It is clear that, with improving technology, multidetector CTA is detecting small, often asymptomatic emboli in patients undergoing CTA for another reason. While it is not clear whether all such patients require therapy, the standard approach at present is to treat [1]. Alarmingly, however, one recent study suggested that cancer patients diagnosed with and treated for incidental pulmonary embolism have the same high rates of recurrent venous thromboembolism, bleeding complications, and mortality, as those who develop symptomatic pulmonary embolism [11].

\section{Ancillary diagnostic testing}

Laboratory testing cannot rule pulmonary embolism in with certainty $[6,8]$. Leukocytosis is much more common with infection than with pulmonary embolism; in one study, among patients with pulmonary embolism in whom other possible or defined causes for leukocytosis were eliminated, 52 of $266(20 \%)$ had a white blood cell count $>10,000 / \mathrm{mm}^{3}$ [12]. D-dimer testing is a very sensitive measurement of fibrinolytic activity but not specific enough to be diagnostic of pulmonary embolism [13]. The D-dimer assay is best utilized in patients with low or moderate clinical probability, and clinical probability models of $\mathrm{D}$-dimer levels have been designed and validated. Increasing D-dimer levels do appear to correlate with increasing mortality [14]. Serum troponin may be positive in acute pulmonary embolism, indicating right ventricular ischemia / microinfarction [15] and this is discussed further under "Risk stratification" below. Brain natriuretic peptide (BNP) levels may also be elevated in acute pulmonary embolism because of right ventricular dilation [16]. This may serve as a clue to the diagnosis, but again is nonspecific.

Arterial blood gas analysis may demonstrate hypoxemia and hypocapnia (decreased $\mathrm{PCO} 2$ ) but may also be normal, particularly in younger patients without cardiopulmonary disease [17]. In the setting of a normal or nearnormal chest radiograph and significant unexplained hypoxemia, pulmonary embolism should be considered. The electrocardiogram is nonspecific in acute pulmonary embolism [18]. It may be normal, or may demonstrate sinus tachycardia or an atrial arrhythmia. In particular, new-onset atrial flutter should increase suspicion of acute

Table I. Risk factors for Venous Thromboembolism*

\begin{tabular}{lll}
\hline Hereditary factors** & Acquired factors* & Probable factors \\
\hline Antithrombin deficiency & Reduced mobility & Elevated homocysteine \\
Protein C deficiency & Advanced age & Elevated factors VIII, IX, XI \\
Protein S deficiency & Cancer & Elevated fibrinogen \\
Factor V Leiden & Acute medical illness & Elevated thrombin-activated fibrinolysis inhibitor \\
Activated protein C resistance without & Pregnancy and the postpartum period & \\
factor V Leiden & Trauma & \\
Prothrombin gene mutation & Spinal cord injury & \\
Plasminogen deficiency & Major surgery & \\
Dysfibrinogenemia & Oral contraceptives & \\
& Hormone replacement therapy & \\
& Polycythemia vera & \\
& Antiphospholipid antibody syndrome & \\
& Heparins & \\
& Chemotherapy & \\
& Obesity & \\
& Central venous catheterization & \\
& Immobilizer or cast & \\
\hline
\end{tabular}

*In a compatible clinical setting, acute deep venous thrombosis and/or pulmonary embolism should be considered even in the absence of known risk factors.

**It remains unclear whether some of the disorders listed above are hereditary, acquired, or both. 
Table 2. Symptoms and Signs in Patients with Acute Pulmonary Embolism Without Preexisting Cardiopulmonary Disease

\begin{tabular}{lclc}
\hline Symptoms & Patients (\%) & Signs & Patients (\%) \\
\hline Dyspnea & 73 & Tachypnea (respiratory rate $\geq 20$ breaths/min) & 70 \\
Pleuritic pain & 66 & Rales/crackles & 51 \\
Cough & 37 & Tachycardia (heart rate $>100$ beats/min) & 30 \\
Leg swelling & 28 & Fourth heart sound & 24 \\
Leg pain & 26 & Increased pulmonary component of second sound & 23 \\
Hemoptysis & 13 & DVT & 11 \\
Palpitations & 10 & Diaphoresis & 11 \\
Wheezing & 9 & Temperature $>38.5^{\circ} \mathrm{C}$ & 7 \\
Angina-like pain & 4 & Wheezes & 5 \\
& & Homans' sign & 4 \\
& Right ventricular lift & 4 \\
& Pleural friction rub & 3 \\
& Third heart sound & 3 \\
\end{tabular}

DVT, deep venous thrombosis.

Adapted from Stein PD, Terrin ML, Hales CA, et al. [17].

pulmonary embolism [19]. The S1Q3T3 pattern may be present on the electrocardiogram, but again is nonspecific. With extensive emboli, a right ventricular strain pattern may be present, which can also be considered with regard to determining the level of aggressiveness for therapy in proven pulmonary embolism (also see "Risk stratification in acute pulmonary embolism" below).

The chest radiograph is often abnormal in acute pulmonary embolism, but may be normal or minimally abnormal [20]. Pulmonary infarction may be associated with pleural-based wedge-shaped infiltrates (Hampton's hump), which may be mistaken for pneumonia, and reduced lung markings associated with an ipsilateral prominent proximal pulmonary artery (Westermark sign) may suggest acute pulmonary embolism. Importantly, echocardiography may identify emboli in-transit in the right atrium and may indicate the diagnosis prior to lung imaging, but this is somewhat unusual, so echocardiography is best used in suspected or proven acute pulmonary embolism to assess the impact of acute pulmonary embolism on right ventricular function. "McConnell's sign" (a regional pattern of right ventricular dysfunction, with akinesia of the mid free wall right ventricular free wall but normal apical contractility) can occur in pulmonary embolism, but acute right ventricular infarction may cause a similar appearance [21].

When pulmonary embolism is suspected, the history and risk factors, physical exam, and ancillary studies should be integrated to form a differential diagnosis and determine the need for specific testing for acute pulmonary embolism. Formulation of a pretest probability can facilitate the clinician's approach. This can be done simply by gestalt, relying on the clinician's experience, comfort level with the disease, and knowledge of the pulmonary embolism literature. However, increasing data support the use of clinical prediction models to guide the diagnostic approach. The most widely studied models include the Wells score [13], the PERC score [22], and the series of Geneva scores [23-25] (Tables 3a-c). While these models have clear utility, a strong clinical suspicion of acute pulmonary embolism should not be ignored solely because a clinical predictive model suggests that it can be.

\section{Diagnostic imaging for suspected pulmonary embolism}

In patients presenting with suspected acute pulmonary embolism, CTA has become the standard diagnostic test in the United States. Echocardiography may establish the diagnosis in certain settings, such as when emboli intransit are visualized in the right atrium.

A normal VQ (ventilation/perfusion) scan rules out pulmonary embolism, and a high probability VQ scan in the setting of suspected pulmonary embolism is essentially diagnostic [26]. However, in the majority of patients with acute pulmonary embolism, VQ scans are not diagnostic [26]. Strong clinical suspicion of pulmonary embolism in the setting of a nondiagnostic VQ scan should lead to another imaging study (CTA, pulmonary angiography, or leg imaging). Ideal candidates with suspected pulmonary embolism to consider for VQ scanning would be younger patients, generally under age 40, without underlying cardiopulmonary disease.

A good quality CTA that is negative for acute pulmonary embolism essentially rules out the diagnosis and specificity is excellent [27]. CTA is also very useful in demonstrating other potential causes of dyspnea and chest pain. In addition, CTA may prove that pulmonary embolism is present when another diagnosis initially appears more 
Table 3. Criteria for the Wells, PERC and revised Geneva score

\begin{tabular}{|c|c|c|}
\hline Table & Feature & Points \\
\hline 3a. The Wells Score* & $\begin{array}{l}\text { PE is most likely diagnosis } \\
\text { Symptoms and signs of DVT present } \\
\text { Heart rate }>100 / \text { minute } \\
\text { Immobilization at least } 3 \text { days, or surgery in previous } 4 \text { weeks } \\
\text { Previous, objectively diagnosed DVT or PE } \\
\text { Hemoptysis } \\
\text { Malignancy with treatment within } 6 \text { months }\end{array}$ & $\begin{array}{l}\text { Yes }=3 \text { points } \\
\text { Yes }=3 \text { points } \\
\text { Yes }=1.5 \text { points } \\
\text { Yes }=1.5 \text { points } \\
\text { Yes }=1 \text { point } \\
\text { Yes }=1 \text { point } \\
\text { Yes }=1 \text { point }\end{array}$ \\
\hline 3b. The PERC Score** & $\begin{array}{l}\text { Age }<50 \text { years } \\
\text { Pulse }<100 / \text { minute } \\
\text { Oxygen saturation }>94 \% \\
\text { Absence of unilateral leg swelling } \\
\text { Absence of Hemoptysis } \\
\text { Recent surgery } \\
\text { Prior DVT/PE } \\
\text { Oral contraceptive use }\end{array}$ & \\
\hline 3c. Revised Geneva score ${ }^{\dagger}$ & $\begin{array}{l}\text { Age }>65 \text { years } \\
\text { Previous DVT or PE } \\
\text { Surgery or fracture within I month } \\
\text { Active malignancy } \\
\text { Hemoptysis } \\
\text { Heart rate } 75 \text { to } 94 / \text { minute } \\
\text { Heart rate }>95 / \text { minute } \\
\text { Unilateral lower limb pain } \\
\text { Pain on deep palpation of lower limb and unilateral edema } \\
0-3 \text { points low probability for acute pulmonary embolism } \\
4-10 \text { points = intermediate probability } \\
>11 \text { points = high probability }\end{array}$ & $\begin{array}{l}1 \\
3 \\
2 \\
2 \\
2 \\
3 \\
5 \\
3 \\
4\end{array}$ \\
\hline
\end{tabular}

\footnotetext{
*In the validation cohort, a score < 4.0 (PE unlikely) combined with a negative Simpli-Red D-dimer assay (not an ELISA-based assay) accurately excluded a diagnosis of acute $\mathrm{PE}$ in $98 \%$ of patients. As per the first 3 point item in the score, gestalt is part of the method; it is not entirely objective. Furthermore, it has been suggested that, commonly, this subjective 3 point "PE most likely" is what tips the score in favor of PE [13].

**The PERC rule was designed to rule out acute PE in patients presenting to the emergency room without further testing. The 8 variables are listed above. As a diagnostic test, low suspicion and PERC negative status has been shown to have a sensitivity of $97.4 \%(\mathrm{Cl} 95.8 \%$ to $98.5 \%)$ and specificity of $21.9 \%$ (Cl $21.0 \%$ to $22.9 \%$ ) [22].

tThe Geneva score was originally designed as a somewhat complex clinical prediction rule which required arterial blood gas analysis. It was ultimately revised, only including clinical data. It was more recently simplified. There are similarities to the Wells score and a recent study suggests that the Wells rule may be more accurate among inpatients and patients presenting to the emergency department, while the revised Geneva score can be used in the emergency department with high reliability.

The simplified Geneva score includes the same parameters as the revised score but the score for each parameter is uniformly I point, and if heart rate is $>95 /$ minute an additional point was added. It is suggested that the likelihood of patients having PE with a simplified Geneva score $<2$ and a normal D-dimer is $3 \%$ [23-25]. Abbreviations: PE, pulmonary embolism; DVT, deep vein thrombosis
}

likely. For example, Tillie-Leblond and colleagues found that there was a $25 \%$ prevalence of pulmonary embolism in patients with COPD (chronic obstructive pulmonary disorder) hospitalized for what was felt to be a COPD exacerbation [28]. Multidetector CTA is quite sensitive, but small, subsegmental emboli are still sometimes difficult to visualize. If a study is suboptimal or if there is doubt, additional lung or leg imaging should be considered.

Imaging of the leg veins by computed tomographic venography can be performed to establish the diagnosis of concomitant deep venous thrombosis, or to look for deep venous thrombosis when the chest CTA is negative, but of course this increases radiation exposure for the patient [29]. Recent data suggest that mortality due to acute pulmonary embolism is higher in the setting of residual deep venous thrombosis, so that evaluating the legs in acute pulmonary embolism may become more common [30].

While pulmonary angiography has been the goldstandard for establishing the diagnosis of acute pulmonary embolism for decades, it is rarely done nowadays [31]. However, an advantage of this technique is the ability to also consider more aggressive catheter-directed techniques in the setting of extensive emboli (see section on treatment below).

Magnetic resonance angiography takes more time to complete than CTA and the diagnostic yield for pulmonary embolism has been shown to be institution dependent [30]. With nephrogenic fibrosing dermopathy in the setting of renal insufficiency, enthusiasm has 
waned. MRA is very sensitive for acute deep venous thrombosis. However, ultrasound is simpler, faster, and adequate in the majority of cases of suspected acute deep venous thrombosis. If chest imaging cannot be performed, ultrasound of the legs can be performed. If deep venous thrombosis is ruled in, the need for therapy is established. [6,32].

In summary, the diagnosis of acute pulmonary embolism requires an integrated approach, often involving more than one test and at least one imaging modality. Prediction rules continue to evolve.

\section{Treatment of acute pulmonary embolism}

The primary goal of treatment in venous thromboembolism is the prevention of thrombus extension and pulmonary embolism. The therapeutic approach is generally the same for deep venous thrombosis and pulmonary embolism [1].

\section{Initial therapy - anticoagulation}

Pulmonary embolism patients with stable hemodynamics appear to have a low death rate when anticoagulated, provided they have no major underlying disease. Thus, such individuals are treated with either low molecular weight heparin or unfractionated heparin [1]. Importantly, anticoagulation should be considered even prior to the diagnosis of pulmonary embolism if the clinical suspicion is high and the risk of bleeding deemed low [1]. The American College of Chest Physicians (ACCP) consensus statement on venous thromboembolism recommends subcutaneous low molecular weight heparin over standard, unfractionated heparin [1]. If unfractionated heparin is used, the bolus and intravenous drip should be weightbased. Table 4 lists advantages of low molecular weight heparin. Once-daily, subcutaneous fondaparinux without monitoring is at least as effective and as safe as intravenous unfractionated heparin in the initial treatment of patients with stable acute pulmonary embolism [33], and has similar advantages over unfractionated heparin as low molecular weight heparin, though renal insufficiency (creatinine clearance $<30 \mathrm{~mL} / \mathrm{min}$ ) is a contraindication. While long-term therapy is beyond our scope, recommendations on duration of anticoagulation are outlined in the ACCP statement [1].

The development of new oral agents for both initial and long-term treatment is likely to ultimately simplify therapy [34]. Direct factor Xa inhibitors, such as rivaroxaban and apixaban target an upstream protease in the clotting cascade, and represent a promising approach in anticoagulation [35-37]. Rivaroxaban and apixaban have recently been approved (in the USA and the E.U. respectively), both are approved for venous thromboembolism prophylaxis in total hip and knee replacement but not for therapy of established acute venous thromboembolism. The results of the EINSTEIN deep venous thrombosis and EINSTEIN EXT studies indicate that rivaroxaban offers an improved risk-benefit profile for acute deep venous thrombosis and is a promising alternative to enoxaparin or oral warfarin [38], and the latter study is ongoing [39]. Dabigatran is a direct thrombin inhibitor that is approved by the FDA for prevention of stroke and blood clots in patients with nonvalvular atrial fibrillation [40,41]. Clinical trials (RE-COVER, RE-MEDY) suggest a favorable risk-benefit profile for dabigatran for the treatment of established venous thromboembolism $[42,43]$ and additional studies are ongoing $[44,45]$.

\section{Thrombolytic agents}

The ACCP currently carries a Grade 1B level of evidence recommendation in support of thrombolytic administration to hemodynamically unstable patients with massive, acute pulmonary embolism in the absence of absolute contraindications [1], and while most clinicians agree, they are often reluctant to pursue this course [46]. A summary of the ACCP recommendations for administration of thrombolytic therapy is outlined in Table 5. Thrombolytic therapy is generally administered by peripheral intravenous

Table 4. Advantages of low molecular weight heparin over standard, unfractionated heparin*

I. Low molecular weight heparin is at least as effective as standard, unfractionated heparin.

2. In certain prophylactic settings, it is more effective than standard, unfractionated heparin**

3. No intravenous line needed with low molecular weight heparin. ${ }^{\dagger}$

4. More bioavailable than standard, unfractionated heparin; thus, generally no monitoring with low molecular weight heparin. ${ }^{\dagger}$

5. Low molecular weight heparin facilitates outpatient therapy.

6. Better quality of life, fewer nosocomial complications with low molecular weight heparin.

7. Less heparin-induced thrombocytopenia with low molecular weight heparin.

\footnotetext{
*Disadvantages include the need to dose adjust low molecular weight heparin for renal insufficiency.

**Examples include total hip/knee replacement, acute stroke with hemiplegia, spinal cord injury.

tMonitoring anti-Xa levels while on low molecular weight heparin can be considered if renal function is changing, with long-term use in pregnancy, in extremes of body weight, or any time absorption or therapeutic levels are questioned.
} 
embolism is higher in the setting of residual deep venous thrombosis, so that evaluation of the legs as part of the risk stratification protocol in acute pulmonary embolism should be considered [30]. High levels of BNP, pro-BNP, and cardiac troponins (both $\mathrm{T}$ and $\mathrm{I}$ ) have been associated with a greater risk of death in patients with pulmonary embolism [63,64]. A meta-analysis of 1,985 pulmonary embolism patients from 20 studies showed that any elevation in troponin level confers a five-fold increase in short-term mortality [65]. Troponin levels predict outcome not only for pulmonary embolism patients in shock but also for those who are hemodynamically stable at presentation. Again, lack of randomization and differing definitions for significant elevation of biomarkers prevent firm conclusions. Factors to be considered for risk stratification are shown in Table 6. The American Heart Association Scientific Statement published in March 2011 offers an excellent literature review and presents a compelling rationale for risk stratification of acute pulmonary embolism patients [66].

\section{Risk stratification in massive pulmonary embolism}

Patients with pulmonary embolism may present with circulatory collapse or respiratory failure; in such extreme settings, risk stratification may simply consist of proof of pulmonary embolism and documentation of significant hypotension. Treatment combines symptomatic interventions to reverse hemodynamic instability and respiratory failure and treatments designed to decrease pulmonary vascular obstruction rapidly $[6,27]$. Transfer to the intensive care unit should be considered in any pulmonary embolism patient with unstable vital signs, significant hypoxemia, or evidence of unstable hemodynamics. Oxygen and intubation with mechanical ventilation are instituted as clinically indicated and administered based upon oxygen saturation/arterial blood gas assessment; the potential detrimental effects of mechanical ventilation on right heart function must be realized.

The traditional first-line treatment for hypotension is volume expansion. Evidence from animal experiments suggests that, in cases of pulmonary hypertension, this may increase myocardial oxygen consumption, resulting in right ventricular ischemia and worsening right ventricular function. Nonetheless, fluid loading may improve the hemodynamic status of patients with massive pulmonary embolism [67].

Vasopressor therapy is still used in the setting of massive pulmonary embolism. However, in experimental animal models with massive pulmonary embolism and severe hypotension, the vasopressor isoproterenol did not prove beneficial and may in fact be detrimental $[68,69]$. In contrast, norepinephrine improved right ventricular function in animal experiments, increasing systemic arterial pressure over a wide range of blood pressure and right ventricular afterloads, suggesting that its effects were not limited to the subset of animals with profound hypotension [70]. This suggests that norepinephrine may be worth considering in patients with massive pulmonary embolism. Evidence relating to the effects of epinephrine in patients with massive pulmonary embolism and shock arises from small case series or single case reports in which patients also received thrombolytic therapy and other vasopressors [71].

\section{Embolectomy and vena caval filter placement}

No clear guidelines can be offered for pulmonary embolectomy. It is reasonable to consider it in patients with proven massive pulmonary embolism and hemodynamic instability, particularly when thrombolytic therapy has failed or is contraindicated $[1,72,73]$. Because these patients are very compromised, the risk of death may be high with this approach. A surgical approach is sometimes considered when there are right heart thrombi, with or without paradoxical embolism, but no data from randomized trials are available; thrombolysis is also commonly considered in such cases.

The primary indications for inferior vena caval filter placement include contraindications to anticoagulation, major bleeding complications during anticoagulation, and recurrent embolism while on therapeutic anticoagulation [1]. Filters are sometimes placed, in the case of massive pulmonary embolism, when it is believed that additional emboli might be lethal, either with or without

\footnotetext{
I. Vital signs (excessive tachycardia/tachypnea, hypotension - unstable hemodynamics is the clearest indication for thrombolytic therapy).

2. Echocardiography (right ventricle enlargement/hypokinesis).

3. Biomarkers (troponin/brain natriuretic peptide).

4. Oxygenation.

5. Clot burden (lung and legs).

6. Comorbid disease/cardiopulmonary reserve.

7. Bleeding risk.
} 
Table 7. Key points in diagnosis/treatment of pulmonary embolism

I. Therapy for acute pulmonary embolism should be initiated if the clinical suspicion is high and the perceived bleeding risk is low.

2. As anticoagulation is initiated and pulmonary embolism is diagnosed, risk stratification should be considered.

3. Depending on the scenario, more aggressive treatment with thrombolytic therapy or embolectomy can be considered.

4. There is now a large body of evidence from large randomized comparisons that unfractionated heparin, low molecular weight heparin and fondaparinux are all safe and effective approaches to initial anticoagulation.

5. Low molecular weight heparin and fondaparinux are easier to administer, do not require monitoring, and are backed by a substantial evidencebase in the modern era.

6. Documented venous thromboembolism in patients with transient risk factors should be treated for 3 to 6 months, but more extended treatment is appropriate when significant risk factors persist, when venous thromboembolism is idiopathic, or when venous thromboembolism is recurrent.

7. Bleeding risk should also be considered.

8. Inferior vena caval filter placement should be undertaken if anticoagulation is contraindicated due to bleeding.

9. Evidence-based guidelines continue to be refined based upon new clinical trial data. New anticoagulants are on the horizon.

thrombolytic therapy. However, this indication is not based on clinical trial data and more data should be acquired. While filters are effective in reducing the incidence of pulmonary embolism, they have been shown to increase the incidence of deep venous thrombosis and have not been shown to increase overall survival [74]. Retrieval is feasible after many months and removal approximately one year after placement has been reported $[75,76]$ but more data are needed to guide this practice. Recommendations for the use of vena caval filters have recently been published [76].

\section{Conclusions}

In summary, acute pulmonary embolism is a potentially fatal disease, and clinicians should be aware of potential risk factors, and the typical and more unusual presentations. Anticoagulation is the standard care for stable patients and should be considered even prior to diagnosis of pulmonary embolism if there is a strong suspicion of pulmonary embolism and the risk of bleeding is deemed low. The presence of unstable hemodynamics is a strong indication for thrombolytic therapy. When anticoagulation is contraindicated, an inferior vena caval filter should be placed. Patients should be risk-stratified and, when appropriate, considered for more aggressive therapy. Given this complexity, risk stratification has become a crucial cornerstone in approaching therapy, but it is still evolving and more data are needed.

\section{Abbreviations}

$\mathrm{BNP}$, brain natriuretic peptide; COPD, chronic obstructive pulmonary disease; CTA, computed tomographic angiography; $\mathrm{VQ}$, ventilation/perfusion.

\section{Competing interests}

The author has received research grants from sanofi Aventis and Bayer, and has received financial compensation for consulting from sanofi Aventis and Bayer in the past year and prior. He has received consulting and lecturing fees more than one year ago from EKOS, Bacchus, Biolex, and Bristol-Myers Squibb prior to one year ago.

\section{References}

I. Kearon C, Kahn SR, Agnelli G, Goldhaber S, Raskob GE, Comerota AJ: Antithrombotic therapy for venous thromboembolic disease: American College of Chest Physicians Evidence-Based Clinical Practice Guidelines (8th Edition). Chest 2008, I33:454S-545S.

2. Dalen JE: Pulmonary embolism: what have we learned since Virchow? Natural history, pathophysiology, and diagnosis. Chest 2002, 122:1440-56.

3. Silverstein MD, Heit JA, Mohr DN, Petterson TM, O'Fallon WM, Melton LJ: Trends in the incidence of deep vein thrombosis and pulmonary embolism: a 25-year population-based study. Arch. Intern. Med 1998, 158:585-93.

4. Sandler DA, Martin JF: Autopsy proven pulmonary embolism in hospital patients: are we detecting enough deep vein thrombosis? J R Soc Med 1989, 82:203-5.

FI000 Factor 8

Evaluated by Victor Tapson 24 April 2012

5. Morgenthaler $\mathrm{TI}$, Ryu JH: Clinical characteristics of fatal pulmonary embolism in a referral hospital. Mayo Clin. Proc 1995, 70:417-24.

FI000 Factor 6

Evaluated by Victor Tapson 24 April 2012

6. Tapson VF: Acute pulmonary embolism. N. Engl. J. Med 2008, 358: 1037-52.

7. Anderson FA, Spencer FA: Risk factors for venous thromboembolism. Circulation 2003, 107:19-16.

FI000 Factor 6

Evaluated by Victor Tapson 24 April 2012

8. Fedullo PF, Tapson VF: Clinical practice. The evaluation of suspected pulmonary embolism. N. Engl. J. Med 2003, 349: 1247-56.

9. Susec $O$, Boudrow $D$, Kline JA: The clinical features of acute pulmonary embolism in ambulatory patients. Acad Emerg Med 1997, 4:891-7.

FI000 Factor 6

Evaluated by Victor Tapson 24 April 2012

10. Le Gal G, Testuz A, Righini M, Bounameaux H, Perrier A: Reproduction of chest pain by palpation: diagnostic accuracy in suspected pulmonary embolism. BMJ 2005, 330:452-3.

FI000 Factor 6

Evaluated by Victor Tapson 24 April 2012

II. den Exter PL, Hooijer J, Dekkers OM, Huisman MV: Risk of recurrent venous thromboembolism and mortality in patients with cancer incidentally diagnosed with pulmonary embolism: a comparison with symptomatic patients. J. Clin. Oncol 20I I, 29:2405-9.

FI000 Factor 6

Evaluated by Victor Tapson 24 April 2012 
12. Afzal A, Noor HA, Gill SA, Brawner C, Stein PD: Leukocytosis in acute pulmonary embolism. Chest 1999, I I5:I329-32.

13. Wells PS, Anderson DR, Rodger M, Stiell I, Dreyer JF, Barnes D, Forgie M, Kovacs G, Ward J, Kovacs MJ: Excluding pulmonary embolism at the bedside without diagnostic imaging: management of patients with suspected pulmonary embolism presenting to the emergency department by using a simple clinical model and d-dimer. Ann. Intern. Med 200I, 135:98-107.

14. Aujesky D, Roy P, Guy M, Cornuz J, Sanchez O, Perrier A: Prognostic value of D-dimer in patients with pulmonary embolism. Thromb. Haemost 2006, 96:478-82.

15. Scridon T, Scridon C, Skali H, Alvarez A, Goldhaber SZ, Solomon SD: Prognostic significance of troponin elevation and right ventricular enlargement in acute pulmonary embolism. Am. J. Cardiol 2005, 96:303-5.

16. Pruszczyk P, Kostrubiec M, Bochowicz A, Styczyński G, Szulc M, Kurzyna M, Fijałkowska A, Kuch-Wocial A, Chlewicka I, Torbicki A: $\mathrm{N}$-terminal pro-brain natriuretic peptide in patients with acute pulmonary embolism. Eur. Respir. J 2003, 22:649-53.

17. Stein PD, Terrin ML, Hales CA, Palevsky HI, Saltzman HA, Thompson BT, Weg JG: Clinical, laboratory, roentgenographic, and electrocardiographic findings in patients with acute pulmonary embolism and no pre-existing cardiac or pulmonary disease. Chest 1991, 100:598-603.

FI000 Factor 6

Evaluated by Victor Tapson 24 April 2012

18. Rodger M, Makropoulos D, Turek M, Quevillon J, Raymond F, Rasuli P, Wells PS: Diagnostic value of the electrocardiogram in suspected pulmonary embolism. Am. J. Cardiol 2000, 86:807-9, AI0.

19. Johson JC, Flowers NC, Horan LG: Unexplained atrial flutter: a frequent herald of pulmonary embolism. Chest 1971, 60:29-34.

FI000 Factor 6

Evaluated by Victor Tapson 24 April 2012

20. Worsley DF, Alavi A, Aronchick JM, Chen JT, Greenspan RH, Ravin CE: Chest radiographic findings in patients with acute pulmonary embolism: observations from the PIOPED Study. Radiology 1993, I89:133-6.

21. Casazza F, Bongarzoni A, Capozi A, Agostoni O: Regional right ventricular dysfunction in acute pulmonary embolism and right ventricular infarction. Eur J Echocardiogr 2005, 6: I I-4.

FI000 Factor 6

Evaluated by Victor Tapson 24 April 2012

22. Kline JA, Courtney DM, Kabrhel C, Moore CL, Smithline HA, Plewa MC, Richman PB, O'Neil BJ, Nordenholz K: Prospective multicenter evaluation of the pulmonary embolism rule-out criteria. J. Thromb. Haemost 2008, 6:772-80.

FI000 Factor 6

Evaluated by Victor Tapson 24 April 2012

23. Wicki J, Perneger TV, Junod AF, Bounameaux H, Perrier A: Assessing clinical probability of pulmonary embolism in the emergency ward: a simple score. Arch. Intern. Med 200 I, I 6 I:92-7.

FI000 Factor 6

Evaluated by Victor Tapson 24 April 2012

24. Le Gal G, Righini M, Roy P, Sanchez O, Aujesky D, Bounameaux H, Perrier A: Prediction of pulmonary embolism in the emergency department: the revised Geneva score. Ann. Intern. Med 2006, |44:|65-7|.

\section{FI000 Factor 9}

Evaluated by Andrew Polmear I4 Mar 2006, Paul Stein I5 Feb 2006

25. Klok FA, Mos ICM, Nijkeuter M, Righini M, Perrier A, Le Gal G, Huisman MV: Simplification of the revised Geneva score for assessing clinical probability of pulmonary embolism. Arch. Intern. Med 2008, 168:2131-6.
26. Value of the ventilation/perfusion scan in acute pulmonary embolism. Results of the prospective investigation of pulmonary embolism diagnosis (PIOPED). The PIOPED Investigators. JAMA 263:2753-9.

27. Konstantinides S: Clinical practice. Acute pulmonary embolism. N. Engl. J. Med 2008, 359:2804-I3.

FI000 Factor 6

Evaluated by Victor Tapson 24 April 2012

28. Tillie-Leblond I, Marquette C, Perez T, Scherpereel A, Zanetti C Tonnel A, Remy-Jardin M: Pulmonary embolism in patients with unexplained exacerbation of chronic obstructive pulmonary disease: prevalence and risk factors. Ann. Intern. Med 2006, | 44:390-6.

FI000 Factor 10

Evaluated by Paul Stein 10 Jul 2006

29. Stein PD, Fowler SE, Goodman LR, Gottschalk A, Hales CA, Hull RD, Leeper KV, Popovich J, Quinn DA, Sos TA, Sostman HD, Tapson VF, Wakefield TW, Weg JG, Woodard PK: Multidetector computed tomography for acute pulmonary embolism. N. Engl. J. Med 2006, 354:2317-27.

30. Jiménez D, Aujesky D, Díaz G, Monreal M, Otero R, Martí D, Marín E, Aracil E, Sueiro A, Yusen RD: Prognostic significance of deep vein thrombosis in patients presenting with acute symptomatic pulmonary embolism. Am. J. Respir. Crit. Care Med 2010, I 8 I:983-91.

FI000 Factor 6

Evaluated by Victor Tapson 24 April 2012

31. Stein PD, Athanasoulis C, Alavi A, Greenspan RH, Hales CA, Saltzman HA, Vreim CE, Terrin ML, Weg JG: Complications and validity of pulmonary angiography in acute pulmonary embolism. Circulation 1992, 85:462-8.

32. Stein PD, Chenevert TL, Fowler SE, Goodman LR, Gottschalk A, Hales CA, Hull RD, Jablonski KA, Leeper KV, Naidich DP, Sak DJ, Sostman HD, Tapson VF, Weg JG, Woodard PK: Gadoliniumenhanced magnetic resonance angiography for pulmonary embolism: a multicenter prospective study (PIOPED III). Ann. Intern. Med 2010, I 52:434-43, WI42-3.

33. Büller HR, Davidson BL, Decousus H, Gallus A, Gent M, Piovella F, Prins $M H$, Raskob G, van den Berg-Segers AEM, Cariou R, Leeuwenkamp O, Lensing AWA: Subcutaneous fondaparinux versus intravenous unfractionated heparin in the initial treatment of pulmonary embolism. N. Engl. J. Med 2003, 349:1695-702.

FI000 Factor 6

Evaluated by Victor Tapson 24 April 2012

34. Bauer KA: Recent progress in anticoagulant therapy: oral direct inhibitors of thrombin and factor $\mathbf{X a}$. J. Thromb. Haemost 201 I, 9(Suppl I): I2-9.

35. Perzborn E, Strassburger J, Wilmen A, Pohlmann J, Roehrig S, Schlemmer $\mathrm{K}$, Straub A: In vitro and in vivo studies of the novel antithrombotic agent BAY 59-7939-an oral, direct Factor Xa inhibitor. J. Thromb. Haemost 2005, 3:5 I4-2I.

36. Wong PC, Crain EJ, Xin B, Wexler RR, Lam PYS, Pinto DJ, Luettgen JM, Knabb RM: Apixaban, an oral, direct and highly selective factor $\mathrm{Xa}$ inhibitor: in vitro, antithrombotic and antihemostatic studies. J. Thromb. Haemost 2008, 6:820-9.

37. Samama MM: The mechanism of action of rivaroxaban-an oral, direct Factor $\mathrm{Xa}$ inhibitor-compared with other anticoagulants. Thromb. Res 201 I, I 27:497-504.

38. Bauersachs R, Berkowitz SD, Brenner B, Buller HR, Decousus $H$, Gallus AS, Lensing AW, Misselwitz F, Prins MH, Raskob GE, Segers A, Verhamme P, Wells P, Agnelli G, Bounameaux H, Cohen A, Davidson BL, Piovella F, Schellong S: Oral rivaroxaban for symptomatic venous thromboembolism. N. Engl. J. Med 2010 , 363:2499-510.

FI000 Factor 6

Evaluated by Victor Tapson 24 April 2012 
39. ClinicalTrials.gov. Oral Direct Factor Xa Inhibitor Rivaroxaban In Patients With Acute Symptomatic Pulmonary Embolism With Or Without Symptomatic Deep-Vein Thrombosis: Einstein-PE Evaluation. Available at: http://clinicaltrials.gov/ct2/show/NCT00439777. Updated July 10, 2011. Accessed October 19, 2011.

40. Stangier J: Clinical pharmacokinetics and pharmacodynamics of the oral direct thrombin inhibitor dabigatran etexilate. Clin Pharmacokinet 2008, 47:285-95.

41. United States Food and Drug Administration. FDA approves Pradaxa to prevent stroke in people with atrial fibrillation [press release]. October 19, 2010. Available at: http://www.fda.gov/NewsEvents/ Newsroom/PressAnnouncements/ucm23024I.htm. Accessed July 28, 2011 .

\section{FI000 Factor 6}

Evaluated by Victor Tapson 24 April 2012

42. Schulman S, Kearon C, Kakkar AK, Mismetti P, Schellong S, Eriksson H, Baanstra D, Schnee J, Goldhaber SZ: Dabigatran versus warfarin in the treatment of acute venous thromboembolism. N. Engl. J. Med 2009, 36 I:2342-52.

FI000 Factor 6

Evaluated by Victor Tapson 24 April 2012

43. Schulman S, Eriksson H, Goldhaber SZ, Lord Kakkar AK, Kearon C, Kvamme AM, Mismetti P, Schellong S, Schnee J: Dabigatran or warfarin for extended maintenance therapy of venous thromboembolism. J Thromb Haemost. 201I, 9(Suppl 2):731. Abstract O-TH-033.

44. ClinicalTrials.gov. Efficacy and Safety of Dabigatran Compared to Warfarin for 6 Month Treatment of Acute Symptomatic Venous Thromboembolism. Available at: http://clinicaltrials.gov/ct2/show/ NCT00329238. Updated February 10, 20I I. Accessed June 3, $201 \mathrm{I}$.

45. ClinicalTrials.gov. Twice-daily Oral Direct Thrombin Inhibitor Dabigatran Etexilate in the Long Term Prevention of Recurrent Symptomatic VTE. Available at: http://clinicaltrials.gov/ct2/show/ NCT00558259. Updated May 4, 20I I. Accessed June 3, $201 \mathrm{I}$.

46. Witty LA, Krichman A, Tapson VF: Thrombolytic therapy for venous thromboembolism: Utilization by practicing pulmonologists. Arch Intern Med 1994, I54:160I-4.

47. Kucher N: Catheter embolectomy for acute pulmonary embolism. Chest 2007, 132:657-63.

FI000 Factor 6

Evaluated by Victor Tapson 24 April 2012

48. Tapson VF, Gurbel PA, Witty LA, Pieper KS, Stack RS: Pharmacomechanical thrombolysis of experimental pulmonary emboli. Rapid low-dose intraembolic therapy. Chest 1994, 106:1558-62.

49. Greenfield LJ, Proctor MC, Williams DM, Wakefield TW: Long-term experience with transvenous catheter pulmonary embolectomy. J. Vasc. Surg 1993, I8:450-7; discussion 457-8.

50. Schmitz-Rode T, Janssens U, Duda SH, Erley CM, Günther RW: Massive pulmonary embolism: percutaneous emergency treatment by pigtail rotation catheter. J. Am. Coll. Cardiol 2000, 36:375-80.

51. Müller-Hülsbeck S, Brossmann J, Jahnke T, Grimm J, Reuter M, Bewig B, Heller M: Mechanical thrombectomy of major and massive pulmonary embolism with use of the Amplatz thrombectomy device. Invest Radiol 2001, 36:317-22.

52. Fava M, Loyola S, Huete I: Massive pulmonary embolism: treatment with the hydrolyser thrombectomy catheter. J Vasc Interv Radiol 2000, I I:I I59-64.

53. Reekers JA, Baarslag HJ, Koolen MGJ, van Delden O, van Beek EJR: Mechanical thrombectomy for early treatment of massive pulmonary embolism. Cardiovasc Intervent Radiol 26:246-50.

54. Margheri M, Vittori G, Vecchio S, Chechi T, Falchetti E, Spaziani G, Giuliani G, Rovelli S, Consoli L, Biondi Zoccai GGL: Early and longterm clinical results of Angiojet rheolytic thrombectomy in patients with acute pulmonary embolism. Am. J. Cardiol 2008, 101:252-8.
55. Chamsuddin A, Nazzal L, Kang B, Best I, Peters G, Panah S, Martin L, Lewis C, Zeinati C, Ho JW, Venbrux AC: Catheterdirected thrombolysis with the Endowave system in the treatment of acute massive pulmonary embolism: a retrospective multicenter case series. J Vasc Interv Radiol 2008, 19:372-6.

56. Aujesky D, Perrier A, Roy P, Stone RA, Cornuz J, Meyer G, Obrosky DS, Fine MJ: Validation of a clinical prognostic model to identify low-risk patients with pulmonary embolism. J. Intern. Med 2007, 261:597-604.

FI000 Factor 6

Evaluated by Victor Tapson 24 April 2012

57. Aujesky D, Obrosky DS, Stone RA, Auble TE, Perrier A, Cornuz J, Roy P, Fine MJ: Derivation and validation of a prognostic model for pulmonary embolism. Am. J. Respir. Crit. Care Med 2005, 172:104|-6.

58. Konstantinides S, Geibel A, Heusel G, Heinrich F, Kasper W: Heparin plus alteplase compared with heparin alone in patients with submassive pulmonary embolism. N. Engl. J. Med 2002, 347: | | 43-50.

FI000 Factor 6

Evaluated by Victor Tapson 24 April 2012

59. Goldhaber SZ, Haire WD, Feldstein ML, Miller M, Toltzis R, Smith JL, Taveira da Silva AM, Come PC, Lee RT, Parker JA: Alteplase versus heparin in acute pulmonary embolism: randomised trial assessing right-ventricular function and pulmonary perfusion. Lancet 1993, 341:507-II.

FI000 Factor 6

Evaluated by Victor Tapson 24 April 2012

60. Ribeiro $A$, Lindmarker $P$, Juhlin-Dannfelt $A$, Johnsson $H$, Jorfeldt $L$ : Echocardiography Doppler in pulmonary embolism: right ventricular dysfunction as a predictor of mortality rate. Am. Heart J 1997, 134:479-87.

FI000 Factor 6

Evaluated by Victor Tapson 24 April 2012

6I. Goldhaber SZ, Visani L, Rosa M de: Acute pulmonary embolism: clinical outcomes in the International Cooperative Pulmonary Embolism Registry (ICOPER). Lancet 1999, 353:1386-9.

FI000 Factor 6

Evaluated by Victor Tapson 24 April 2012

62. Pruszczyk P, Bochowicz A, Torbicki A, Szulc M, Kurzyna M, Fijałkowska A, Kuch-Wocial A: Cardiac troponin T monitoring identifies high-risk group of normotensive patients with acute pulmonary embolism. Chest 2003, 123:1947-52.

FI000 Factor 6

Evaluated by Victor Tapson 24 April 2012

63. Kostrubiec M, Pruszczyk P, Bochowicz A, Pacho R, Szulc M, Kaczynska A, Styczynski G, Kuch-Wocial A, Abramczyk P, Bartoszewicz Z, Berent H, Kuczynska K: Biomarker-based risk assessment model in acute pulmonary embolism. Eur. Heart J 2005, 26:2166-72.

64. Becattini C, Vedovati MC, Agnelli G: Prognostic value of troponins in acute pulmonary embolism: a meta-analysis. Circulation 2007, I I6:427-33.

FI000 Factor 8

Evaluated by Jane Freedman 07 Aug 2007

65. Kucher N, Walpoth N, Wustmann K, Noveanu M, Gertsch M: QR in $V I-a n$ ECG sign associated with right ventricular strain and adverse clinical outcome in pulmonary embolism. Eur. Heart J 2003, 24: I II3-9.

FI000 Factor 6

Evaluated by Victor Tapson 24 April 2012 
66. Jaff MR, McMurtry MS, Archer SL, Cushman M, Goldenberg N Goldhaber SZ, Jenkins JS, Kline JA, Michaels AD, Thistlethwaite P, Vedantham S, White RJ, Zierler BK: Management of massive and submassive pulmonary embolism, iliofemoral deep vein thrombosis, and chronic thromboembolic pulmonary hypertension: a scientific statement from the American Heart Association. Circulation 20II, I23:1788-830.

FI000 Factor 6

Evaluated by Victor Tapson 24 April 2012

67. Mercat A, Diehl JL, Meyer G, Teboul JL, Sors H: Hemodynamic effects of fluid loading in acute massive pulmonary embolism. Crit. Care Med 1999, 27:540-4.

FI000 Factor 6

Evaluated by Victor Tapson 24 April 2012

68. Layish DT, Tapson VF: Pharmacologic hemodynamic support in massive pulmonary embolism. Chest 1997, I I I:2 18-24.

69. McDonald IG, Hirsh J, Hale GS, Cade JF, McCarthy RA: Isoproterenol in massive pulmonary embolism: haemodynamic and clinical effects. Med. J. Aust 1968, 2:20I-5.

FI000 Factor 6

Evaluated by Victor Tapson 24 April 2012

70. Ghignone M, Girling L, Prewitt RM: Volume expansion versus norepinephrine in treatment of a low cardiac output complicating an acute increase in right ventricular afterload in dogs. Anesthesiology 1984, 60:132-5.

FI000 Factor 6

Evaluated by Victor Tapson 24 April 2012

7I. Boulain T, Lanotte R, Legras A, Perrotin D: Efficacy of epinephrine therapy in shock complicating pulmonary embolism. Chest 1993, 104:300-2.

FI000 Factor 6

Evaluated by Victor Tapson 24 April 2012
72. Leacche M, Unic D, Goldhaber SZ, Rawn JD, Aranki SF, Couper GS, Mihaljevic T, Rizzo RJ, Cohn LH, Aklog L, Byrne JG: Modern surgical treatment of massive pulmonary embolism: results in 47 consecutive patients after rapid diagnosis and aggressive surgical approach. J. Thorac. Cardiovasc. Surg 2005, 129:1018-23.

FI000 Factor 6

Evaluated by Victor Tapson 24 April 2012

73. Meyer G, Tamisier D, Sors H, Stern M, Vouhé P, Makowski S, Neveux JY, Leca F, Even P: Pulmonary embolectomy: a 20-year experience at one center. Ann. Thorac. Surg 1991, 51:232-6.

74. Decousus H, Leizorovicz A, Parent F, Page Y, Tardy B, Girard P, Laporte S, Faivre R, Charbonnier B, Barral FG, Huet Y, Simonneau G: A clinical trial of vena caval filters in the prevention of pulmonary embolism in patients with proximal deep-vein thrombosis. Prévention du Risque d'Embolie Pulmonaire par Interruption Cave Study Group. N. Engl. J. Med 1998, 338: 409-15.

FI000 Factor 6

Evaluated by Victor Tapson 24 April 2012

75. Mismetti P, Rivron-Guillot $K$, Quenet $S$, Décousus $H$, Laporte $S$, Epinat M, Barral FG: A prospective long-term study of 220 patients with a retrievable vena cava filter for secondary prevention of venous thromboembolism. Chest 2007, I3 I: 223-9.

FI000 Factor 6

Evaluated by Victor Tapson 24 April 2012

76. Kaufman JA, Kinney TB, Streiff MB, Sing RF, Proctor MC, Becker D, Cipolle M, Comerota A], Millward SF, Rogers FB, Sacks D, Venbrux AC: Guidelines for the use of retrievable and convertible vena cava filters: report from the Society of Interventional Radiology multidisciplinary consensus conference. J Vasc Interv Radiol 2006, 17:449-59.

FI000 Factor 6

Evaluated by Victor Tapson 24 April 2012 